\title{
Intergroup food transfers in wild golden lion tamarins (Leontopithecus rosalia)
}

\author{
Camille A. Troisi ${ }^{1,2}$ (1)
}

Received: 31 March 2020 / Accepted: 6 July 2020

(c) The Author(s) 2020

\begin{abstract}
The transfer of food between adults is uncommon in primates. Although golden lion tamarins (Leontopithecus rosalia) are unique among primates in the extent to which they transfer food, reports of food transfers between adults have so far been restricted to captive or reintroduced individuals. Here, I report the first recorded events of adult-adult food transfers in golden lion tamarins between individuals belonging to different groups in the wild. Given that individuals emigrate from their natal group to find reproductive opportunities, I suggest that intergroup food transfers could be a way for individuals to estimate the quality or availability of potential mates or social partners. I propose an additional function of food transfers in wild golden lion tamarins: that they create and strengthen social bonds with individuals outside of the family group.
\end{abstract}

Keywords Food transfers $\cdot$ Social bond $\cdot$ Intergroup interaction $\cdot$ Golden lion tamarins $\cdot$ Tolerance

\section{Introduction}

Within-group food transfers are common in primates, particularly in apes and callitrichids (Brown et al. 2004), and can serve several functions. Here, the term food transfer refers to any behavioural interaction that involves the passage of food between two individuals, including begging, stealing and offering (see Brown et al. 2004), without implying any intentionality on either side. Most transfers are passive, where the donor allows the receiver to take food from them (Brown et al. 2004), and most occur between mothers and infants (Brown et al. 2004; Feistner and McGrew 1989). Adult-adult food transfer is rare and is only present in species that also transfer food to their young (Jaeggi and Van Schaik 2011). A common function of transfers is hence to provide young with food or information, but between adults, food transfers can be used to avoid harassment (Brown et al. 2004; Feistner and McGrew 1989; Jaeggi and Van Schaik 2011). In support of this second function, most adult-adult food transfers in primates are predicted by dominance, with

Camille A. Troisi

camille.troisi@mail.mcgill.ca

1 School of Biology, University of St Andrews, St Andrews, UK

2 School of Biological, Earth and Environmental Sciences, University College Cork, Cork, Ireland higher ranking individuals taking food from lower ranking individuals, with relinquishing food being the least costly strategy for the lower ranking individual (Brown et al. 2004). Thirdly, some work on chimpanzees suggests that food transfers between group members are used for social support, or that food is exchanged for sexual interaction (Mitani and Watts 2001; Nishida et al. 1992). Finally, there is also evidence of reciprocal altruism involving food transfers in capuchins and tamarins in captivity (Brown et al. 2004). However, Cheney and Seyfarth (1990) suggest that reciprocity in primates is more likely to involve social interactions rather than physical objects, such as food.

By contrast, between-group food transfers are almost unknown in primates. Recently, Fruth and Hohmann (2018) reported an event where an individual bonobo (Pan paniscus) possessing an antelope shared part of it with members of its own group as well as members of the neighbouring community, but comparable observations do not exist for many other commonly studied primates. We might expect to see between-group transfers when there is high tolerance between groups, such as when the cost of aggression is high, or when resources are not defensible (Robinson and Barker 2017).

The Callitrichidae is a unique family not only because of the extensive transfer of food from adults to juveniles, potentially for both nutritional and informational benefits (Brown et al. 2005; Feistner and Chamove 1986; Moura et al. 2010; 
Moura and Langguth 1999; Rapaport 1999; Troisi 2017; Troisi et al. 2020; Voelkl et al. 2006), but also because of the prevalence of active transfers initiated by adults (Brown et al. 2004; Feistner and McGrew 1989), especially towards juveniles and pregnant females (Guerreiro Martins et al. 2019; Ruiz-Miranda et al. 1999). Recent work has shown that food transfers in callitrichids can also be used to reinforce cooperative bonds within a group (Guerreiro Martins et al. 2019).

The golden lion tamarin (Leontopithecus rosalia) is an endangered callitrichid native to the Atlantic forest on the southeastern coast of Brazil. They are territorial cooperative breeders that live in small family groups, with an average group size of five to seven individuals (Dietz et al. 1994; Dietz and Baker 1993; Tardiff et al. 2002; Troisi 2017; Troisi et al. 2018, 2020). Golden lion tamarins have a rapid reproductive turnover, often giving birth to twins, and show intense parental investment (Dietz et al. 1994). They defend a territory of approximately $45.2 \pm 15.5$ ha against other golden lion tamarin groups (Dietz et al. 1997), and have regular, highly vocal encounters with neighbouring groups (Peres 1989). One study reported that intergroup encounters, including both face-to-face and long-range encounters, occurred on average once every 2.1 and 1.6 days per year of the study, respectively (Peres 1989). Another study reported intergroup interactions in two groups in $11.6 \%$ and $2.2 \%$ of scan samples, respectively (Dietz et al. 1997). Most golden lion tamarins disperse from their natal groups, mainly by emigrating to neighbouring groups, with $60 \%$ of individuals dispersing from their natal group by 3 years of age and $90 \%$ after 4 years of age (Baker et al. 2002).

Unlike most primates, golden lion tamarins actively provision young and other group members with solid food (Rapaport and Brown 2008), and adults vocalise to infants to offer them food (Brown and Mack 1978; Rapaport 2011; Rapaport and Ruiz-Miranda 2002). Experimental studies show that golden lion tamarins preferentially transfer to juveniles food items that are rare, that the donors have eaten before, or that are difficult to process or novel (Price and Feistner 1993; Rapaport 1999, 2006; Troisi et al. 2020), but adults also transfer food to pregnant females (Ruiz-Miranda et al. 1999). However, despite food transfers being common, all reported transfers occurred between members of the same group, and transfers between adults have only been reported in captive or reintroduced individuals.

The function of intergroup food transfers still raises a large number of questions. High tolerance between groups or resource defence have been suggested as the driving force behind intergroup food transfers (Robinson and Barker 2017). Interestingly, the social and physical structure of golden lion tamarins' environment does not predispose them to between-group food transfers, as they are highly territorial and aggressive towards non-group members, and mainly feed on fruits and insects that can be monopolised (Robinson and Barker 2017). Here I describe six events in the wild where food that could be monopolised was transferred (i.e. successfully changed hands) between members of different groups of golden lion tamarin. These interactions between two individuals included individuals offering the food in their possession to another individual, but also events where one individual attempted to obtain a food item from another individual by emitting vocalisations, by reaching out an arm in the direction of the food, or by directly grabbing the food. Given that the previously hypothesised drivers of food transfers between groups have not been found for golden lion tamarins, this is an interesting species to study to further our understanding of the function of intergroup food transfers.

\section{Materials and methods}

Six groups of golden lion tamarins comprising from three to 10 free-living individuals ( $n=42$ individuals in January-March 2014, and $n=46$ individuals in August-September 2014) were observed in two locations in the Atlantic forest, Brazil. In each group, all of the individuals were related to the breeding pair of that group, with the exception of one individual in three of the groups. Three of the groups were located in the Poço das Antas Biological Reserve (PDA) $\left(22^{\circ} 30^{\prime}-22^{\circ} 33^{\prime} \mathrm{S}, 42^{\circ} 15^{\prime}-42^{\circ} 19^{\prime} \mathrm{W}\right)$, and the three other groups in a pocket of Atlantic forest in the Fazenda Afetiva-Jorge (FAJ), Imbaú region $\left(22^{\circ} 37^{\prime} \mathrm{S}, 42^{\circ} 28^{\prime} \mathrm{W}\right)$. The sites, which are less than $30 \mathrm{~km}$ apart, are in the municipality of Silva Jardim, Rio de Janeiro, Brazil, and have similar plant species (Carvalho et al. 2006). Table 1 shows the composition of each group for which observations are reported here (for a list of all the individuals of each group, see Table S1, ESM). The groups were habituated to human presence and monitored by members of the Associação Mico-Leão-Dourado. To keep track of the population, each group was regularly surveyed to record births and deaths, and individuals were captured twice a year to weigh, measure and individually mark them on the tail and body with Nyanzol dye. Individuals were also tattooed at first capture as part of the management of the species by the Associação Mico-Leão-Dourado (Ruiz-Miranda et al. 1999).

The observations reported here were made during two experiments designed to study teaching behaviour in golden lion tamarins, during which food was provided to groups in the wild (Troisi et al. 2018, 2020). In the first experiment, golden lion tamarins were provided with small samples of different types of food, i.e. bananas, apples, grapes, mealworms and crickets in January-February 2014, and additionally pears and papayas in August-September 2014 (Troisi et al. 2020). The fruits were cut into small pieces/slices, and 
Table 1 Group composition during the observation period

\begin{tabular}{llll}
\hline Group & Location & Male:female & $\begin{array}{c}\text { Adults:subadults } \\
\text { :juveniles:infants }\end{array}$ \\
\hline AF2 & Fazenda Afetiva-Jorge & $6: 6$ & $5: 3: 2: 2$ \\
Super & Fazenda Afetiva-Jorge & $2: 7$ & $3: 3: 1: 2$ \\
AF & Poço das Antas Biological Reserve & $2: 3$ & $4: 1: 0: 0$ \\
BO2 & Poço das Antas Biological Reserve & $5: 3$ & $6: 2: 0: 0$ \\
\hline
\end{tabular}

Adults are $>18$ months old, sub-adults are between 9 and 18 months old, juveniles are between 3 and 9 months old, and infants are $<3$ months old the insects were dehydrated. All food items were provided in pots (Fig. 1a). The aim of the experiment was to examine the function of adult to juvenile within-group food transfers. In this experiment, very few individuals ate the dehydrated insects, and all of the transfers observed were of fruits. In the second experiment, the same golden lion tamarin groups were provided with a novel substrate containing slices of bananas in February-March 2014 and September-October 2014 (Troisi et al. 2018) (Fig. 1b), with the aim of determining whether juvenile golden lion tamarins learn substrate properties from food-offering calls (Troisi et al. 2018). In both experiments, territorial encounters took place during some of the trials, allowing me to make the observations that I report below.

All electronic supplementary materials are available at OSF (https://osf.io/8w5gj/).

\section{Results}

I observed six food transfers between individuals of different groups (Table 2; ESM video). All of the transfers reported below involved six unique donors and six unique receivers. One individual (BO2T13) was a donor in one of the observations and a receiver in another observation, thus $n=11$. In each food transfer, individuals were from different natal groups and unrelated to each other. The first three observations were made during the first experiment investigating food transfers using different types of food (Troisi et al. 2020), and the remaining three observations during the second experiment, which examined the function of foodoffering calls (Troisi et al. 2018).

A total of 128 experimental trials were carried out on the study population during the two experiments reported in Troisi et al. $(2018,2020)$. An individual from another group was observed during 17 of these experimental trials of a focal group. These 17 trials included the six observations of intergroup food transfer (from four different trials) reported here. In addition, the focal group was displaced by another group in two of the trials. Hence, an intergroup encounter was recorded in $14.8 \%$ (19/128) of the total number of trials.

\section{Observation 1}

The first observation was made on 1 February 2014 at Fazenda Affetiva-Jorge. Five individuals, four from group AF2 and one from group Super, were foraging on provisioned fruits at a platform before briefly dispersing. The following individuals from group AF2 were present: AF2T3, a sub-adult male; AF2T13, a juvenile male; AF2T2, a juvenile female; and AF2T34 a sub-adult female. The individual from group Super was SuperT3, a sub-adult female (1 year 3 months old). After dispersal to branches around the

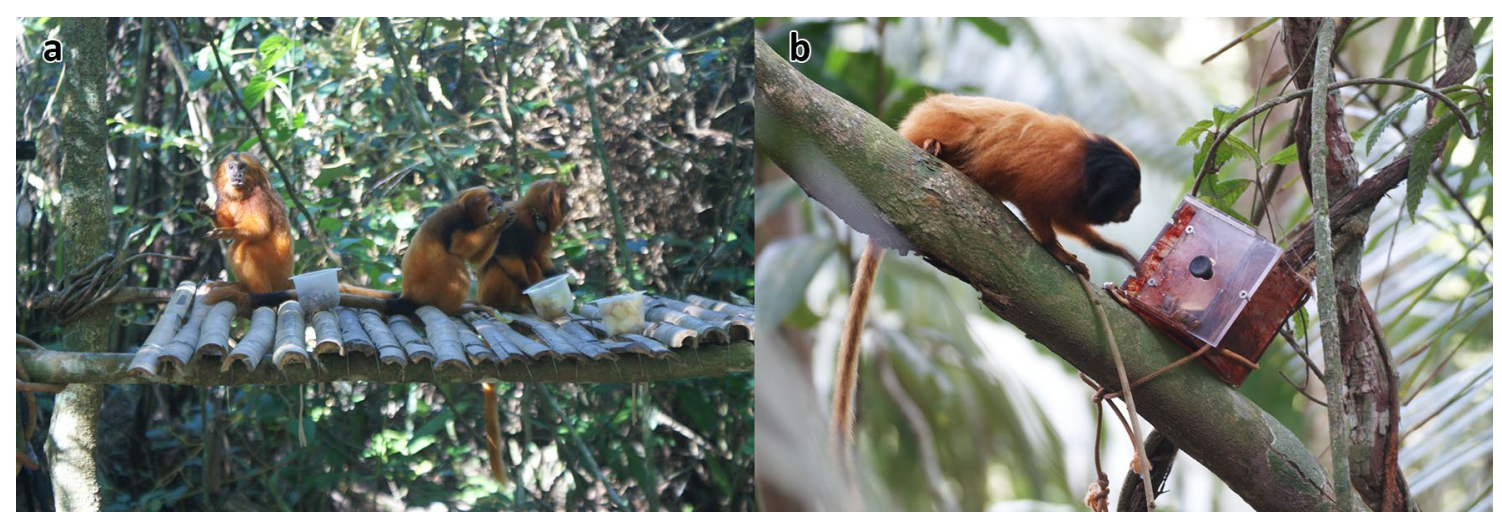

Fig. 1 a Photo of the food-transfer experiment; $\mathbf{b}$ photo of the food-offering-call experiment 


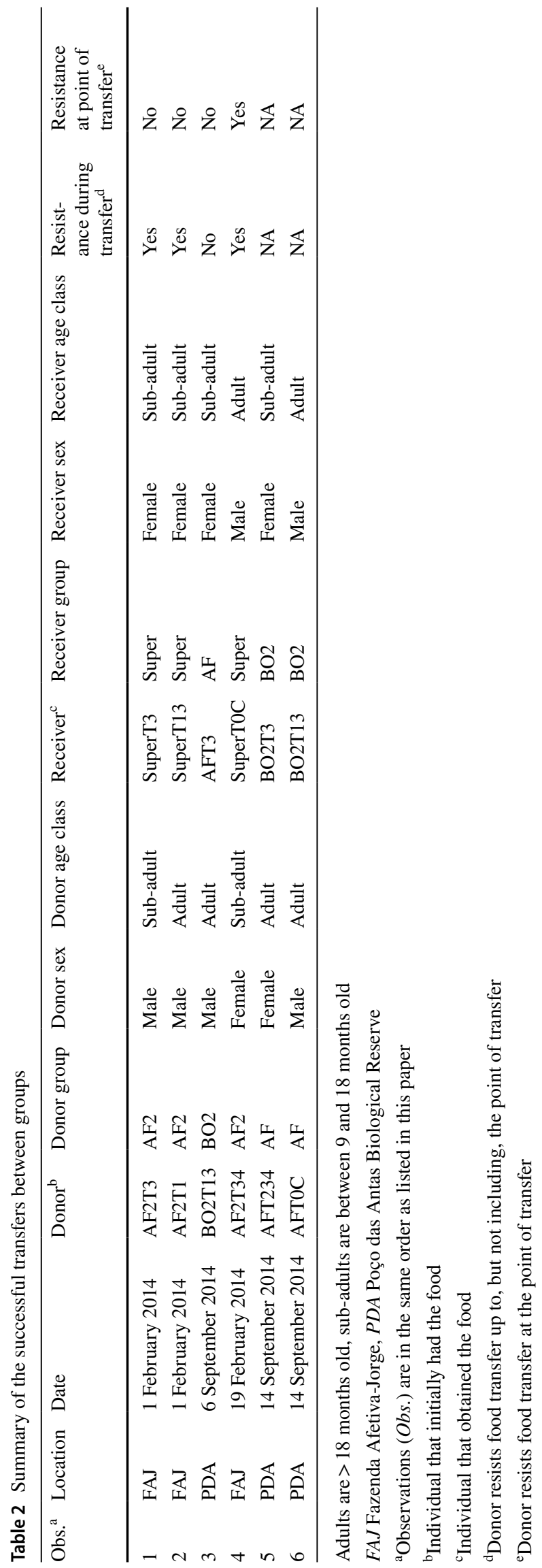

platform, SuperT3 approached individual AF2T3, who was foraging on a piece of grape. SuperT3 extended her arm and hand four times towards AF2T3 and vocalised before AF2T3 appeared to let her take the food from his hand.

\section{Observation 2}

The second observation occurred 21:48 min after the first one. Two individuals from AF2 (AF2T2, a juvenile female; and AF2T14, an adult male) and one individual from Super (SuperT3, from observation 1) were foraging on a platform when they were approached by individual SuperT13, a sub-adult female (1 year 3 months old) from group Super. AF2T12, an adult female carrying two infants, and AF2T23, an adult female, were also in the vicinity of the platform. SuperT13 first inspected some of the food on the platform before approaching AF2T14, then first attempted to take a grape from AF2T14's mouth. AF2T14 showed some resistance to this, but then appeared to let SuperT13 take the food from his hand. SuperT13 was then approached by a juvenile from the AF2 group, potentially to take the food, which led SuperT13 to leave the platform. During this entire period, SuperT3 was foraging on another food patch less than $15 \mathrm{~cm}$ away from where the food transfer took place.

\section{Observation 3}

The third observation took place on 6 September 2014 at the Poço das Antas Biological Reserve. AFT3, a sub-adult female from group AF, was foraging in the presence of two other individuals (AFT234, an adult female from group $\mathrm{AF}$, and an unidentified individual, potentially also from group $\mathrm{AF}$ ), when $\mathrm{BO} 2 \mathrm{~T} 13$, an adult male from group $\mathrm{BO}$, approached the pot of food where AFT3 (11 months old) was foraging. $\mathrm{BO} 2 \mathrm{~T} 13$ started extracting a piece of grape from the pot, but AFT3 took it from BO2T13's hands and ate it, with little resistance from BO2T13. During the transfer, $\mathrm{BO} 2 \mathrm{~T} 2$, a sub-adult male from group $\mathrm{BO} 2$, was in the vicinity of the pot.

\section{Observation 4}

This observation, and the following two, were made during the food-offering call experiment (Troisi et al. 2018) where a novel substrate containing banana was provided to the groups. On 19 February 2014 at Fazenda AffetivaJorge, three individuals were foraging on the novel substrate: one from group Super (SuperT0C, an adult male) and two from group AF2 (AF2T4, a sub-adult male; and AF2T34, a sub-adult female). AF2T34 obtained food from the substrate and was eating some banana when SuperT0C (3 years 4 months old) arrived to investigate the substrate, then tried to get some banana from AF2T34's hands. AF2T34 showed 
some resistance, but SuperT0C obtained the food nonetheless. SuperT3, a sub-adult female, and SuperT1, a juvenile female, both from group Super, approached the group during the transfer.

\section{Observation 5}

The firth observation occurred on 14 September 2014 at the Poço das Antas Biological Reserve. Four individuals from group AF were present: AFT3, a sub-adult female; AFT0C, an adult male; AFT234, an adult female; and AFT1234, an adult female; as well as one individual from group $\mathrm{BO}$, $\mathrm{BO} 2 \mathrm{~T} 3$, a sub-adult female. AFT234 was extracting food from the novel substrate when BO2T3 (12 months old) intercepted the food and obtained part of the slice of banana that AFT234 had been trying to extract. BO2T3 actually attempted to get food from AFT0C, an adult male from group AF, and from AFT3, a sub-adult female from group $\mathrm{AF}$, in the $12 \mathrm{~s}$ preceding the successful transfer from AFT234. However, both of these former attempts were unsuccessful (i.e. BO2T3 did not obtain any food).

\section{Observation 6}

The sixth observation occurred $15 \mathrm{~s}$ after the fifth one. AFT1234, AFT0C and AFT234 from group AF were foraging at the platform, and $\mathrm{BO} 2 \mathrm{~T} 3$, from group $\mathrm{BO} 2$, was eating the transferred piece of banana nearby, when $\mathrm{BO} 2 \mathrm{~T} 13$, an adult male (1 year 7 months old) from group $\mathrm{BO} 2$ approached the substrate. AFT0C was extracting food from the substrate when $\mathrm{BO} 2 \mathrm{~T} 13$ reached up from below and grabbed the piece of banana before AFT0C could put it in his mouth. BO2T13 left the area immediately after having obtained the food.

In the first three observations the individual who initially had the food stopped resisting before the second individual obtained the food. In each of these transfers the individual who initially had the food was male and the individual who obtained it was female. Two of the donor males were adults (>18 months old), and one was a subadult (between 10 and 18 months old), while all three of the receiver females were subadults. In the fourth observation, where the food was transferred from a sub-adult female to an adult male, the adult male received the food despite the sub-adult female resisting at the point of transfer. In the last two observations, in which the food was transferred from an adult female to a sub-adult female (fifth observation), and from an adult male to another adult male (sixth observation), the transfer of food took place quickly, and I was unable to see whether there was any resistance during the transfer.

\section{Discussion}

The six observations reported here show that the transfer of food between strangers is not unique to humans or other great apes. In each case, the food items that were transferred could have been obtained individually, without any requirement for cooperation or specialised skills. This is particularly true for observations $1-3$ as food was available in several areas other than the place where the food transfer occurred. In these three cases, individuals could have easily taken food directly from the pots, and even sometimes from individuals of their own group. In observations 4-6, however, there was only one source of food present, leading to congregation around the device. This lack of multiple food sources in observations 4-6 could have meant that it was easier for an individual to obtain food from another individual, even if that individual was from another group, than obtain food from the device, despite the agonistic interaction that could have arisen as a consequence of this. However, these six food transfer events were very similar to those that occur between individuals of the same group.

These instances of transfer of food between members of different groups of golden lion tamarin may show, for the first time, a level of tolerance in this species similar to that seen in bonobos (Fruth and Hohmann 2018). However, the social structures of golden lion tamarins and bonobos are very different: while bonobos show moderate aggression towards other individuals, including individuals of other communities, and live in fission-fusion groups within a community, golden lion tamarins are aggressive towards potential immigrants, and live in a family-structured group where offspring emigrate, on average, when they are around 2.5 years old (Baker and Dietz 1996; Fruth and Hohmann 2018; Romano et al. 2019). Moreover, unlike in bonobos, the food resources that were transferred between the golden lion tamarins could have been easily monopolised by just one individual. Both the social and physical structure of golden lion tamarins' environment are very different to those of other primate species, such as bonobos, in which intergroup food transfers have been observed. It is therefore unlikely that tolerance between different groups or resource defence help explain intergroup food transfers in golden lion tamarins, and likely that this type of sharing between groups evolved independently in different primate linages. In primates, there is evidence that food transfers may be used by females to test a male's tolerance (Goffe and Fischer 2016; van Noordwijk and van Schaik 2009; Yamamoto 2015). Yamamoto (2015) proposed a begging-for-social-bond hypothesis, in which individuals beg to strengthen social bonding as well as to gain access to food. Although insufficient, if supported 
by further experiments, the observations described here would indicate that this hypothesis is applicable to species other than those of great apes, and also that social bonds may extend beyond a group. Given that the observations of golden lion tamarins reported here violate previous expectations of which social and environmental conditions drive food transfers between groups, additional work on this species could further our understanding of the function of intergroup food transfers.

Although food transfers between different groups of golden lion tamarins could be indicative of a new level of social tolerance in this species, it is important to note that they are highly territorial, with intergroup interactions usually being aggressive (French and Inglett 1989; Peres 1989; Ruiz-Miranda et al. 2002). During dispersal events, resident golden lion tamarins are also aggressive toward immigrants (Baker and Dietz 1996), so the six observations of food transfer between individuals of different groups reported here are particularly interesting, and also inconsistent with previously suggested functions of food transfer in this species. In golden lion tamarins, food transfers have mainly been studied in the context of providing nutrition or information to juveniles, or nutrition to pregnant females. Here I suggest that food transfers may be used to create and/or strengthen social bonds with non-group members.

Subordinate golden lion tamarins have two main reproductive options: to wait for a breeding opportunity in their natal group, while caring for the young of the breeding pair, or to emigrate to explore their own breeding opportunities (Romano et al. 2019). Both male and female golden lion tamarins disperse from their natal group and settle in the first available breeding position or unoccupied area that they encounter; however, males tend to disperse more frequently than females, and are more successful when dispersing (Baker and Dietz 1996; Dietz and Baker 1993; Moraes et al. 2018; Romano et al. 2019). Furthermore, males and females use different strategies to emigrate: males are more likely to immigrate into established groups, whereas females are more likely to form new groups (Romano et al. 2019), and are also more likely to inherit their natal territory than males (Baker and Dietz 1996). Leaving the natal group for reproduction is very risky for tamarins, but encounters with neighbouring groups provide opportunities to identify potential sexual partners or new group members (Nascimento et al. 2014). Food transfers between individuals of different groups could therefore be used to create a social bond prior to immigration, which could either facilitate acceptance and reduce aggression when immigrating to a new group, or enable individuals to find social partners to form a new group with. Work on captive callitrichids suggests that immigration might be limited by aggression from resident individuals, with female residents being particularly intolerant of other females (e.g., French and Inglett 1989; French and Snowdon 1981; Harrison and Tardif 1989). Food transfers with members of a different group could therefore be a potential mechanism to recruit new members into a group by modulating the level of tolerance towards unfamiliar conspecifics (French and Inglett 1989). Food transfers with individuals from a different group, particularly with individuals of a different sex, might enable future immigrants to assess their likelihood of being integrated into a new group, or of finding a mate. Miller et al. (2003) found evidence that scent markings are not used for territorial defence in golden lion tamarins, but might be used as a way to communicate information for mate selection, extra-group copulation, and/ or to attract immigrant partners. Food transfers could similarly be used to decrease aggression in order to communicate information beyond the group. If food transfers are indeed used as a means of creating a social bond with non-group individuals prior to dispersal, one would expect individuals involved in between-group food transfers to be of an age to disperse. According to Romano et al. (2019) natal emigration occurs around 2.5 years of age (range: $12-70$ months). All the receivers of the between-group transfers in the six reported observations were within this range, except for one tamarin which was 11 months old, and all the receivers were younger than 2.5 years old, except for one which was 3 years 4 months old. The age of the donors was more variable, i.e. from 1 year 4 months to 7 years 4 months, but all the donors were within the age range given by Romano et al. (2019) except for one individual. However, we would not necessarily expect the age of a donor to fall within the natal emigration age range, as the receiver might be immigrating into the donor's group, whereas the donor might not necessarily emigrate.

Romano et al. (2019) found that conspecific attraction, where individuals leave their natal group because they are attracted to potential extra-group mates and/or emigrating group mates, characterises emigration for both male and female golden lion tamarins. Food transfers might be a way of assessing potential extra-group mate quality or acceptance, and Hankerson and Dietz (2014) suggest that males in particular might prospect neighbouring groups for breeding opportunities. Hence food transfers might be particularly useful for males deciding where and when to immigrate to reduce the probability of eviction. Romano et al. (2019) also found evidence for parallel dispersal (emigration with peers or close kin) in golden lion tamarins. Since females are more likely to start new groups than males, they might evaluate potential mates or social partners for this through intergroup food transfers. Long-term data are required to determine whether individuals involved in food transfers with members of other groups then immigrate preferentially into these groups, or start new groups with members who have shown tolerance towards them. 
Four out of the six observations reported here were food transfers between individuals of different sex: in three observations $(1,2,3)$ the food went from a male to a female, while in one observation (4) it went from a female to a male. These four observations might be examples of individuals assessing the quality of a potential mate through food transfer prior to dispersing. If so, these observations would support the sexual selection hypothesis, which postulates the occurrence of competition in the choice of a mate (West-Eberhard 1983). However, two of the observations were of food transfer between individuals of the same sex: in observation 5 the food went from a female to a female, and in observation 6 the food went from a male to a male. It is possible that instead of being a means of helping a tamarin to choose between potential mates, these food transfer events also help individuals to select a future social partner prior to dispersing. It is also interesting to note that the two food transfers between individuals of the same sex took place rapidly, and were more akin to what is described in the literature as "food stealing". Overall, I suggest that food transfer to a member of a different group may be a means of creating a social bond with that individual, especially prior to dispersal. Further data are required to assess which of these outcomes is more likely to primarily drive food transfers between adults of different groups.

One limitation of the observations reported here is that they were made during an experiment where food items were provided to golden lion tamarin groups. Thus it is possible that the increase in food availability induced an atypical level of tolerance towards non-group members, resulting in the observed food transfers. However, I think it is unlikely that the increase in food availability created this high level of tolerance because half of the observations $(3,5$, and 6$)$ were made during the fruiting season, when so much food was available that it was sometimes difficult to interest the groups in the fruit provided in the experiments, as they were more interested in the fruit in the trees. Furthermore, some experiments undertaken on tamarins in captivity have indicated that food transfers are less likely when food is abundant (e.g. Price and Feistner 1993) because it is easier for the tamarins to acquire food personally instead of getting it from another individual. Moreover, although interactions between different groups are usually quite aggressive initially, they can last several hours, and lose intensity over time (Peres 1989). During face-to-face encounters, when no experiments are taking place, individual golden lion tamarins still forage, although less than at other times (Peres 1989). When a group's territory overlaps with that of another group and when encounters de-escalate, individuals from different groups have been observed feeding on the same tree (C. R. Ruiz-Miranda, personal communication). Although not widely reported in the literature, this is relatively common, particularly in large ficus trees (C. R. Ruiz-Miranda, personal communication). Juveniles from different groups have also been observed playing together, without much interference from adults (C. R. Ruiz-Miranda, personal communication), suggesting a certain level of tolerance, at least towards some individuals. Hence, given those observations, it seems probable that food transfers between individuals of different groups occur outside of the context of human provisioning.

\section{Conclusion}

Most previous work on food transfers in golden lion tamarins has focussed on transfers from adults to young to determine whether the function of the transfer is to provide nutrition, information or both (Price and Feistner 1993; Rapaport 1999; Troisi et al. 2020). Up until now, adultadult food transfers have only been reported in captive or reintroduced individuals (Ruiz-Miranda et al. 1999). Here there is not only evidence of adult-adult food transfers in the wild, but also of food transfers between individuals of different groups, which is inconsistent with the previously suggested functions of food transfers in this species. I suggest an additional function of food transfers in wild golden lion tamarins: that they create and/or strengthen social bonds with individuals outside of the family group, which could be particularly useful for tamarins prior to immigrating to a new group or founding a new group with individuals from other groups. Although the function of intergroup encounters in lion tamarins is not fully understood, the six observations reported here contribute to the growing body of literature showing the flexibility of social behaviour in callitrichids. Taken together, the different functions of food transfers in wild populations of primates offer us insights into their social behaviour (Goffe and Fischer 2016).

Acknowledgements I want to thank Kevin Laland and Will Hoppitt, who supported my research while the observations discussed in this article were made. I also want to thank Will Hoppitt and James Savage, as well as the anonymous reviewers, for providing crucial feedback on an earlier version of the manuscript, and Kevin Laland, who provided funding for the fieldwork. I want to thank Carlos Ruiz-Miranda for providing access to the field site, field equipment and personnel, and for information about tamarin relatedness. I also want to thank the Associação Mico-Leão-Dourado for logistic support, and particularly Andrea Martins, Ademilson de Oliveira, and Jadir Ramos from the Metapopulacao team, as well as Lunara Joia, Carlos Alberto Pereira Junior, and Patricia Santiago for their help in the field during the two experiments. Last but not least, I would also like to thank Katherine Meacham for providing support throughout the project.

Author contributions C. A. T. made the observations and wrote the manuscript.

Funding The research was supported in part by a grant from the John Templeton Foundation (40128) and the European Research Council (232823) to K. N. Laland. 


\section{Compliance with ethical standards}

Conflict of interest The author declares that she has no conflict of interest.

Ethical approval All experiments were performed in accordance with the American Society of Primatologists' Principles for the Ethical Treatment of Primates and the Association for the Study of Animal Behaviour guidelines. The Animal Welfare and Ethics Committee of the University of St Andrews approved the studies. The Instituto Chico Mendes de Conservação da Biodiversidade approved the ethics for project no. 17409-0, Manejo de metapopulação do Mico-Leão-Dourado: pesquisa e ações, which met the legal requirements of Brazil.

Open Access This article is licensed under a Creative Commons Attribution 4.0 International License, which permits use, sharing, adaptation, distribution and reproduction in any medium or format, as long as you give appropriate credit to the original author(s) and the source, provide a link to the Creative Commons licence, and indicate if changes were made. The images or other third party material in this article are included in the article's Creative Commons licence, unless indicated otherwise in a credit line to the material. If material is not included in the article's Creative Commons licence and your intended use is not permitted by statutory regulation or exceeds the permitted use, you will need to obtain permission directly from the copyright holder. To view a copy of this licence, visit http://creativecommons.org/licenses/by/4.0/.

\section{References}

Baker AJ, Dietz JM (1996) Immigration in wild groups of golden lion tamarins (Leontopithecus rosalia). Am J Primatol 38:47-56

Baker AJ, Bales K, Dietz JM (2002) Mating system and group dynamics in lion tamarins. In: Kleiman DG, Rylands AB (eds) Lion tamarins: biology and conservation. Smithsonian Institution Press, Washington, pp 188-2012

Brown K, Mack DS (1978) Food sharing among captive Leontopithecus rosalia. Folia Primatol 29:268-290

Brown GR, Almond REA, van Bergen Y (2004) Begging, stealing, and offering: food transfer in nonhuman primates. Advances in the study of behavior, 34th edn. Elsevier, New York, pp 265-295. https://doi.org/10.1016/S0065-3454(04)34007-6

Brown GR, Almond REA, Bates NJ (2005) Adult-infant food transfer in common marmosets: an experimental study. Am J Primatol 65(4):301-312. https://doi.org/10.1002/ajp.20117

Carvalho FA, Nascimento MT, Braga JMA (2006) Composição e riqueza florística do componente arbóreo da Floresta Atlântica submontana na região de Imbaú, Município de Silva Jardim, RJ. Acta Bot Bras 20(3):727-740. https://doi.org/10.1590/S0102 $-33062006000300022$

Cheney DL, Seyfarth RM (1990) How monkeys see the world: inside the mind of another species. University of Chicago Press, Chicago

de Moura AC, Langguth A (1999) The function of food sharing with infants in the golden-head-lion tamarin (Leontopithecus chrysomelas). In: Twenty-second annual meeting of the American Society of Primatologists, vol 49, p 81

de Moura AC, Nunes HG, Langguth A (2010) Food sharing in lion tamarins (Leontopithecus chrysomelas): does foraging difficulty affect investment in young by breeders and helpers? Int J Primatol 31(5):848-862. https://doi.org/10.1007/s10764-010-9432-4

Dietz JM, Baker AJ (1993) Polygyny and female reproductive success in golden lion tamarins, Leontopithecus rosalia. Anim Behav 46:1067-1078
Dietz JM, Baker AJ, Miglioretti D (1994) Seasonal variation in reproduction, juvenile growth, and adult body mass in golden lion tamarin. Am J Primatol 34:115-132. https://doi.org/10.1002/ ajp.1350340204

Dietz JM, Peres CA, Pinder L (1997) Foraging ecology and use of space in wild golden lion tamarins (Leontopithecus rosalia). Am J Primatol 41:289-305

Feistner ATC, Chamove AS (1986) High motivation toward food increases food-sharing in cotton-top tamarins. Dev Psychobiol 19(5):439-452. https://doi.org/10.1002/dev.420190505

Feistner ATC, McGrew WC (1989) Food sharing primates critical review. In: Seth $\mathrm{P}$, Seth $\mathrm{S}$ (eds) Perspectives in primate biology, 3rd edn. Today and Tomorrow's, New Delhi, pp 21-36

French JA, Inglett BJ (1989) Female-female aggression and male indifference in response to unfamiliar intruders in lion tamarins. Anim Behav 37:487-497. https://doi.org/10.1016/0003-3472(89)90095 $-X$

French JA, Snowdon CT (1981) Sexual dimorphism in responses to unfamiliar intruders in the tamarin, Saguinus oedipus. Anim Behav 29(3):822-829. https://doi.org/10.1016/S0003 $-3472(81) 80016-4$

Fruth B, Hohmann G (2018) Food sharing across borders: first observation of intercommunity meat sharing by bonobos at LuiKotale. DRC Hum Nat 29(2):91-103. https://doi.org/10.1007/s1211 0-018-9311-9

Goffe AS, Fischer J (2016) Meat sharing between male and female Guinea baboons (Papio papio). Primate Biol 3(1):1-8. https:// doi.org/10.5194/pb-3-1-2016

Guerreiro Martins EM, Moura A, Finkenwirth C, Griesser M, Burkart J (2019) Food sharing patterns in three species of callitrichid monkeys (Callithrix jacchus, Leontopithecus chrysomelas, Saguinus midas): individual and species differences. J Comp Psychol 133(4):474-487. https://doi.org/10.1037/com0000169

Hankerson SJ, Dietz JM (2014) Predation rate and future reproductive potential explain home range size in golden lion tamarins. Anim Behav 96:87-95. https://doi.org/10.1016/j.anbehav.2014.07.026

Harrison ML, Tardif SD (1989) Species differences in response to conspecific intruders in Callithrix jacchus and Saguinus oedipus. Int J Primatol 10(4):343-362. https://doi.org/10.1007/BF02737421

Jaeggi AV, Van Schaik CP (2011) The evolution of food sharing in primates. Behav Ecol Sociobiol 65(11):2125-2140. https://doi. org/10.1007/s00265-011-1221-3

Miller KE, Laszlo K, Dietz JM (2003) The role of scent marking in the social communication of wild golden lion tamarins Leontopithecus rosalia. Anim Behav 65(4):795-803. https://doi. org/10.1006/anbe.2003.2105

Mitani JC, Watts DP (2001) Why do chimpanzees hunt and share meat? Anim Behav 61(5):915-924. https://doi.org/10.1006/ anbe. 2000.1681

Moraes AM, Ruiz-Miranda CR, Galetti PM Jr, Niebuhr BB, Alexandre BR, Muylaert RL, Grativol AD, Ribeiro JW, Ferreira AN, Ribeiro MC (2018) Landscape resistance influences effective dispersal of endangered golden lion tamarins within the Atlantic Forest. Biol Cons 224:178-187. https://doi.org/10.1016/j.biocon.2018.05.023

Nascimento ATA, Nali C, da Fonseca GAB (2014) Dispersal, group formation and kinship in the black-faced lion tamarin (Leontopithecus caissara). Folia Primatol 85(4):216-227. https://doi. org/10.1159/000363058

Nishida T, Hasegawa T, Hayaki H, Takahata Y, Uehara S (1992) Meatsharing as a coalition strategy by an alpha male chimpanzees? Topics in primatology: human origins, 1 st edn. Univeristy of Tokyo Press, Tokyo, pp 159-174

Peres CA (1989) Costs and benefits of territorial defense in wild golden lion tamarins Leontopithecus rosalia. Behav Ecol Sociobiol 25(3):227-233. https://doi.org/10.1007/BF00302922 
Price EC, Feistner ATC (1993) Food sharing in lion tamarins: tests of three hypotheses. Am J Primatol 31(3):211-221. https://doi. org/10.1002/ajp.1350310306

Rapaport LG (1999) Provisioning of young in golden lion tamarins (Callitrichidae, Leontopithecus rosalia): a test of the information hypothesis. Ethology 105(7):619-636. https://doi.org/10.10 46/j.1439-0310.1999.00449.x

Rapaport LG (2006) Provisioning in wild golden lion tamarins (Leontopithecus rosalia): benefits to omnivorous young. Behav Ecol 17(2):212-221. https://doi.org/10.1093/beheco/arj016

Rapaport LG (2011) Progressive parenting behavior in wild golden lion tamarins. Behav Ecol 22(4):745-754. https://doi.org/10.1093/ beheco/arr055

Rapaport LG, Brown GR (2008) Social influences on foraging behavior in young nonhuman primates: learning what, where, and how to eat. Evol Anthropol Issues News Rev 17(4):189-201. https://doi. org/10.1002/evan.20180

Rapaport LG, Ruiz-Miranda CR (2002) Tutoring in wild golden lion tamarins. Int J Primatol 25(5):1063-1070

Robinson EJH, Barker JL (2017) Inter-group cooperation in humans and other animals. Biol Lett 13(3):20160793. https://doi. org/10.1098/rsbl.2016.0793

Romano V, Martins AF, Ruiz-Miranda CR (2019) Unraveling the dispersal patterns and the social drivers of natal emigration of a cooperative breeding mammal, the golden lion tamarin. Am J Primatol 81(3):e22959. https://doi.org/10.1002/ajp.22959

Ruiz-Miranda CR, Kleiman DG, Dietz JM, Moraes E, Grativol AD, Baker AJ, Beck BB (1999) Food transfers in wild and reintroduced golden lion tamarins, Leontopithecus rosalia. Am J Primatol 48:305-320

Ruiz-Miranda CR, Archer CA, Kleiman DG (2002) Acoustic differences between spontaneous and induced long calls of golden lion tamarins Leontopithecus rosalia. Folia Primatol 73(2-3):124-131. https://doi.org/10.1159/000064791

Tardiff SD, Santos CV, Baker AJ, van Elsacker L, Feistner ATC, Kleiman DG, Vleeschouwer K (2002) Infant care and development in lion tamarins. Lion tamarins: biology and conservation. Smithsonian Institution Press, Washington, pp 213-232

Troisi CA (2017) An investigation of teaching behaviour in primates and birds. University of St Andrews, St Andrews

Troisi CA, Hoppitt WJE, Ruiz-Miranda CR, Laland KN (2018) Food-offering calls in wild golden lion tamarins (Leontopithecus rosalia): evidence for teaching behavior? Int J Primatol 39(6):1105-1123. https://doi.org/10.1007/s10764-018-0069-z

Troisi CA, Hoppitt WJE, Ruiz-Miranda CR, Laland KN (2020) The role of food transfers in wild golden lion tamarins (Leontopithecus rosalia): support for the informational and nutritional hypothesis. Primates. https://doi.org/10.1007/s10329-020-00835-0

van Noordwijk MA, van Schaik CP (2009) Intersexual food transfer among orangutans: do females test males for coercive tendency? Behav Ecol Sociobiol 63(6):883-890. https://doi.org/10.1007/ s00265-009-0728-3

Voelkl B, Schrauf C, Huber L (2006) Social contact influences the response of infant marmosets towards novel food. Anim Behav 72(2):365-372. https://doi.org/10.1016/j.anbehav.2005.10.013

West-Eberhard MJ (1983) Sexual selection, social competition, and speciation. Q Rev Biol 58(2):155-183. https://doi. org/10.1086/413215

Yamamoto S (2015) Non-reciprocal but peaceful fruit sharing in wild bonobos in Wamba. In: Hare B, Yamamoto S (eds) Bonobo cognition and behaviour. Brill, Leiden

Publisher's Note Springer Nature remains neutral with regard to jurisdictional claims in published maps and institutional affiliations. 